\title{
RESISTÊNCIA ANTIMICROBIANA DE ESCHERICHIA COLI ISOLADA DE AVES COMERCIAIS
}

Cardoso, A.L.S.P.; Tessari, E.N.C.; Luciano, R.L.; Zanatta, G.F; Kanashiro, A.M.I.

Centro Avançado de Pesquisa Avícola, Instituto Biológico. Rua Bezerra Paes, 2278, CEP 13690-000, Descalvado, SP, Brasil. E-mail: alspcardoso@biologico.sp.gov.br.

\section{RESUMO}

Em aves as linhagens de Escherichia coli patogênicas, são classificadas como Avian Pathogenic Escherichia coli (APEC), destacando-se como um dos principais agentes responsáveis por perdas econômicas na indústria avícola. A utilização de antimicrobiano constitui uma tecnologia eficientemente aplicada na avicultura, mas o amplo uso de drogas antibacterianas, para o tratamento de possíveis infecções e como promotores de crescimento, permite o aparecimento de linhagens resistentes. O objetivo desse estudo foi avaliar o perfil de resistência antimicrobiana de cepas de E. coli isoladas de amostras avícolas como matrizes, poedeiras e frango de corte, do Estado de São Paulo. Isolou-se 76 cepas de E. coli, que foram submetidas ao teste de suscetibilidade a doze antimicrobianos de oito classes diferentes. Observou-se que alta resistência a maioria das drogas testadas, sendo que 82,8\% para amoxicilina, $65,8 \%$ para enrofloxacina, $56,5 \%$ para cefalexina e 52,6 para estreptomicina. O perfil de multirresistência foi identificado em $78,9 \%$ das amostras, tendo o índice MAR entre 0,08 a 0,90 . É necessário realizar o teste de suscetibilidade para monitorar os níveis de resistência e realizar a melhor escolha do medicamento a ser utilizado.

Palavras chaves: APEC, Escherichia coli, resistência antimicrobiana 


\section{ABSTRACT}

\section{ANTIMICROBIAN RESISTANCE OF Escherichia coli ISOLATED FROM COMMERCIAL BIRDS}

In birds the pathogenic Escherichia coli strains are classified as Avian Pathogenic Escherichia coli (APEC), standing out as one of the main agents responsible for economic losses in the poultry industry. The use of antimicrobial is a technology efficiently applied in poultry farming, but the wide use of antibacterial drugs, for the treatment of possible infections and as growth promoters, allows the appearance of resistant strains. The objective of this study was to evaluate the antimicrobial resistance profile of $E$. coli strains isolated from poultry samples as matrices, laying hens and broilers from the State of São Paulo. Seventy-six strains of $E$. coli were isolated and tested for susceptibility to twelve antimicrobials from eight different classes. It was observed that high resistance to most of the drugs tested, being $82.8 \%$ for amoxicillin, $65.8 \%$ for enrofloxacin, $56.5 \%$ for cephalexin and 52.6 for streptomycin. The multiresistance profile was identified in $78.9 \%$ of the samples, with MAR index between 0.08 and 0.90 . It is necessary to perform the susceptibility test to monitor resistance levels and to make the best choice of medicine to be used.

Key-words: APEC, Escherichia coli, antimicrobial resistance

O habitat natural de Escherichia coli é o trato entérico de humanos e outros animais de sangue quente (GRIFFIN; STUART, 1940). E. coli, tem sido amplamente estudada, devido aos seus diferentes mecanismos de virulência e por estar relacionada com diversas doenças no homem e nos animais (NAKAZATO et al., 2009). Em aves as linhagens de E. coli patogênicas, são classificadas como Avian Pathogenic Escherichia coli (APEC) (FERREIRA; KNOBL, 2000; GOMIS et al., 2001). A APEC destaca-se como um dos principais agentes responsáveis por perdas econômicas na indústria avícola (ITO et al., 2007), sendo associadas a diferentes quadros infecciosos atuando como agente primário ou secundário, podendo ser controlada por medidas profiláticas e uso de antibióticos (MCMULLIN, 2004).

A utilização de antimicrobiano constitui uma tecnologia eficientemente aplicada na indústria avícola, muito utilizada para minimizar os danos causados por infecções causadas por $E$. coli e reduzir as perdas econômicas (GIUROV et al., 1981; SILVA, 2008).

O amplo uso de drogas antibacterianas, para o tratamento de possíveis infecções e como promotores de crescimento, permite o aparecimento de linhagens resistentes, sendo isso um fato cada vez mais comum, com graves consequências à indústria avícola e à saúde da população consumidora devido à possibilidade de transferência horizontal de resistência entre microrganismos co- 
mensais e patogênicos (BLANCO et al., 1997; COHEN, 2000).

Várias pesquisas demonstram a ocorrência de $E$. coli isoladas de aves, resistentes aos medicamentos mais utilizados em avicultura (ZANATTA et al., 2004; GONÇALVES; ANDREATTI FILHO, 2010; CARDOSO et al., 2014; MOHAMED et al., 2014). Portanto, monitorar a resistência de bactérias isoladas de aves a diferentes grupos de antibióticos torna-se um fator determinante para a eleição da droga utilizada no tratamento.

O objetivo deste estudo foi verificar o perfil de resistência de cepas de $E$. coli isoladas de aves comerciais, frente a doze antimicrobianos, com a finalidade de demostrar a importância de eleger o medicamento correto, baseado na realização do antibiograma.

No período de janeiro de 2016 a maio de 2018 foram enviadas ao Centro Avançado de Pesquisa Avícola-Instituto Biológico, Descalvado, SP, aves comerciais (matrizes de frangos de corte, reprodutoras de postura, frango de corte e pintinhos) proveniente do Estado de São Paulo. As aves foram necropsiadas e colheu-se material dos órgãos (fígado, coração, ovidutos e sacos aéreos) com lesões macroscópicas sugestivas de colibacilose.

Para o isolamento bacteriano os suabes e fragmentos de órgãos foram inoculados em caldo $\mathrm{BHI}$ (Brain Heart Infusion) e incubados a $36^{\circ} \mathrm{C} \pm 1$ por 24 hs. Posteriormente, o material foi inoculado em placas contendo ágar sangue e ágar Mac Conkey e incubados a $36^{\circ} \mathrm{C}$ \pm 1 por $24 \mathrm{hs}$. Após esse período as colô- nias com características típicas de E. coli foram confirmadas através de triagem e série bioquímica. Para a metodologia bacteriológica seguiu-se as recomendações descritas por BARNES et al. (2003). Foram isoladas 76 cepas de $E$. coli.

Os isolados de $E$. coli foram submetidos ao teste de sensibilidade a 12 antimicrobianos com as respectivas concentrações, de oito classes diferentes: amoxicilina (10 $\mathrm{mcg}$ ), canamicina (30 $\mathrm{mcg}$ ), cefalexina (30 mcg), ciprofloxacina $(5 \mathrm{mcg})$ doxiclina $(30 \mathrm{mcg})$, enrofloxacina (5 mcg), estreptomicina (10 mcg), fosfomicina (200 mcg), gentamicina (10 $\mathrm{mcg}$ ), norfloxacina (10 mcg), sulfametoxazol e trimetoprim $(25 \mathrm{mcg})$, tetraciclina (30 mcg). A metodologia utilizada seguiu o método de difusão em placa descrito pelo Clinical and Laboratory Standards Institute (CLSI, 2013).

O índice de múltipla resistência aos antimicrobianos (MAR) foi calculado conforme metodologia descrita por KRUMPERMAN (1983), sendo este índice determinado pela relação entre o número de antimicrobianos que a amostra é resistente e o número total de antimicrobianos testados. Índice MAR acima de 0,2 caracteriza multirresistência.

Foram isoladas 76 cepas de E. coli para as quais foram submetidas ao teste de suscetibilidade com doze drogas antimicrobianos de oito classes diferentes. Foi observada resistência contra todas as drogas testadas. $O$ antimicrobiano que apresentou maior percentual de resistência foi a amoxicilina com 63 cepas resistentes $(82,8 \%)$, seguido por enrofloxacina com $50(65,8 \%)$; cefalexina 43 
$(56,5 \%)$ e estreptomicina com 40 isola- dos antibiogramas e as classes dos antidos resistentes $(52,6 \%)$. Os resultados bióticos estão demonstrados na Tabela 1.

TABELA 1. Perfil de resistência de 76 cepas de $E$. coli, isoladas de aves comerciais, aos 12 antimicrobianos testados, de oito classes diferentes.

\begin{tabular}{lcccc} 
Classe de Antibiótico & Antibiótico & $\begin{array}{c}\text { Resistente } \\
\mathbf{N}^{\circ}(\%)\end{array}$ & $\begin{array}{c}\text { Sensível } \\
\mathbf{N}^{\circ}(\%)\end{array}$ & $\begin{array}{c}\text { Intermediário } \\
\mathbf{N}^{\circ}(\%)\end{array}$ \\
\hline Cenicilina & Amoxicilina & $63(82,8)$ & $13(17,2)$ & - \\
\hline Aminoglicosídeos & Cefalexina $\left(1^{\circ}\right)$ & $43(56,6)$ & $33(43,4)$ & - \\
\cline { 2 - 5 } & Gentamicina & $10(13,2)$ & $66(86,8)$ & - \\
\cline { 2 - 5 } & Estreptomicina & $40(52,6)$ & $36(47,4)$ & - \\
\hline Quinolonas & Canamicina & $36(47,4)$ & $40(52,6)$ & - \\
\hline Fluorquinolonas & Ciprofloxacina & $13(17,1)$ & $63(82,9)$ & - \\
\hline Tetraciclinas & Norfloxacina & $11(14,5)$ & $65(85,5)$ & - \\
\hline Sulfonamidas & Enrofloxacina & $50(65,8)$ & $26(34,2)$ & - \\
\hline Outras & Tetraciclina & $26(34,2)$ & $50(65,8)$ & - \\
\hline & Doxiciclina & $33(43,4)$ & $43(56,6)$ & - \\
\hline
\end{tabular}

As cepas de E. coli apresentaram em sua maioria grande espectro de multirresistência aos antimicrobianos testados, sendo que 60 amostras $(78,9 \%)$ das cepas foram multirresistentes, ou seja, revelaram resistência a mais de três classes diferentes de drogas e tiveram o índice MAR acima de 0,2; conforme descrito na Tabela 2.

TABELA 2. Índices de múltipla resistência a antimicrobianos (MAR) encontrados nos isolados de $E$. coli de aves comerciais.

\section{Índice MAR}

\begin{tabular}{cll}
\hline 00 & 01 \\
\hline 0,08 & 07 \\
\hline 0,16 & 06 \\
\hline 0,25 & 13 \\
\hline 0,34 & 11 \\
\hline 0,40 & 06 \\
\hline 0,50 & 12 \\
\hline 0,70 & 12 \\
\hline 0,80 & 02 \\
\hline 0,90 & 04 \\
\hline
\end{tabular}


Neste estudo, verificamos que as amostras de $E$. coli, isoladas de aves comerciais apresentaram altos coeficientes de resistência aos antimicrobianos, normalmente utilizados na avicultura. As drogas amoxicilina, enrofloxacina, cefalexina, estreptomicina são as drogas que tiveram alto índice de resistência. Esses dados corroboram com o que já foi observado em outras pesquisas como ZANATTA et al. (2004); GONÇALVES et al. (2012) e CARDOSO et al. (2015).

A presença de alta resistência a diferentes drogas em cepas de E. coli patogênica para aves, tem preocupado os vários segmentos da avicultura mundial (OBENG et al., 2012). O excesso de antibióticos usados na produção de alimentos de origem animal tem contribuído para o surgimento de resistência bacteriana, sendo esta uma causa de preocupação mundial (GARCIA-MIGURA et al., 2014).

STELLA et al. (2016), relatou que estreptomicina foi resistente a $79,1 \%$ dos isolados de $E$. coli oriundos de aves, em nosso estudo essa droga foi a quarta mais resistente, tendo índice de 52,6 $\%$. BARROS et al. (2012) isolaram 35 amostras de $E$. coli de frangos de corte e poedeira comercial e evidenciaram alta percentagem de resistência à amoxicilina e enrofloxacina, corroboram com nossos resultados. $\mathrm{Na}$ pesquisa realizada por MOHAMED et al. (2014), foi relatado elevada taxa de resistência a amoxicilina e enrofloxacina, $100 \%$ e $88 \%$ respectivamente. KIM et al. (2007) também detec- taram alta resistência a enrofloxacina. A alta taxa de resistência a enrofloxacina é provavelmente decorrente do uso excessivo desse antibiótico para fins terapêuticos e de prevenção em aves (MOHAMED et. al., 2014).

Estreptomicina foi a quarta droga mais resistente, nesse estudo, ficando com índice de 52,6\%, esse antimicrobiano vem sendo utilizado a várias décadas e os níveis de resistência vem aumentando (BASS et al., 1999; ZHAO et al., 2005; KIM et al., 2007).

CARDOSO et al. (2015), verificaram que as cepas foram resistentes a tetraciclina e à sulfametozaxol/trimetoprim, já nessa pesquisa essas drogas não apresentaram alto níveis de resistência, ficando em $34,2 \%$ e $25 \%$ respectivamente, isso pode ser decorrente da proibição desses antimicrobianos, pela legislação brasileira (BRASIL, 1998) como aditivos alimentares, promotores de crescimento ou como conservantes de alimentos para animais. Conforme NEPOMUCENO et al. (2016), a alta sensibilidade do conjugado sulfametozaxol/trimetoprim se deve ao sinergismo dos dois fármacos que amplia o espectro de ação e soma da performance. Seus resultados do grupo das tetraciclinas foi o menos eficiente. A doxiciclina e a tetraciclina apresentaram sensibilidade inferior a $60 \%$, justificando a causa da redução do uso destes antimicrobianos na terapêutica de aves. BRITO et al. (2011) observaram que E. coli isoladas de lesões de celulite de frangos de corte oriundo de criações do Paraná 
também apresentaram resistência enrofloxacina $(62 \%)$, tetraciclina $(21 \%)$, doxiciclina (4\%) e sulfonamida (46\%).

Em nossa pesquisa, as cepas de $E$. coli demonstraram perfil de multirresistência em 60 das 76 amostras isoladas (78,9\%). Taxas altas de multirresistência $94,2 \%$, também foram observadas por BARROS et al. (2012) quando analisaram cepas desse patógeno isoladas de frangos de corte e poedeiras comerciais. A resistência da $E$. coli a pelo menos, duas classes de antimicrobianos é um achado comum, tanto na medicina humana quanto na veterinária, causando um crescente impacto em opções terapêuticas viáveis (VON BAUM; MARRE, 2005).

Quando analisado o perfil de sensibilidade dos grupos de antimicrobianos formados, autores observaram que a maioria das amostras foram sensíveis, com maior destaque ao grupo das pleuromutilinas $(93 \%)$, seguidos dos aminoglicosídeos $(88 \%)$ e quinolonas/fluoroquinolonas $(77 \%)$. Dentre as cepas isoladas, $30,76 \%$ apresentaram resistência a pelo menos dois antimicrobianos testados, recomendados para tratamento de aves (NEPOMUCENO et al., 2016).

Foi determinado o índice de MAR das cepas de E. coli, onde observou-se que os resultados obtidos demonstraram variação entre 0,08 a 0,90. Outros autores como BARROS et al. (2012) e CARDO$S O$ et al. (2015), verificaram em seus estudos variação do índice MAR, dados esses semelhantes aos nosso estudo. NE-
POMUCENO et al. (2016) observaram que $24,56 \%$ das cepas isoladas apresentaram multirresistência aos antimicrobianos testados. O índice MAR serve como uma informação adicional do potencial patogênico das amostras (KRUMPERMAN, 1983). ADELEKE; OMAFUVBE (2011) mencionaram que índices MAR superiores a 0,2 são de antimicrobianos utilizados frequentemente.

MOTA et al. (2005) consideram que a utilização indiscriminada de antimicrobianos favorece a seleção de resistência a antimicrobianos. Assim, a avaliação do perfil de resistência tem grande importância devido aos fármacos utilizados na medicina humana e veterinária pertencerem as mesmas classes de drogas NEPOMUCENO et al. (2016)

O uso de antibióticos pela indústria animal tem sido associado à emergência de cepas resistentes de bactérias. Além disso, a possibilidade de resíduos de drogas em produtos à base de carne é uma questão importante, especialmente para o comércio internacional. Por estas razões, a indústria da produção animal procura reduzir o uso de antibióticos (GOMIS et al., 2001).

Decorrente do perfil de resistência apresentado pelas cepas de E. coli faz-se necessário a realização de testes de sensibilidade aos antimicrobianos para a melhor escolha do medicamento a ser utilizado.

Nessa pesquisa podemos concluir que cepas de E. coli isolados de aves comerciais como matrizes, frango de corte, 
postura comercial, foram resistente aos antimicrobianos. Os resultados deste estudo demonstram que amoxicilina, enrofloxacina, cefalexina e estreptomicina.
O índice MAR variou entre 0,08 a 0,90, sendo que a maioria das cepas tiveram MAR superior a 0,2 indicando o perfil de multirresistência.

\section{REFERÊNCIAS BIBLIOGRÁFICAS}

ADELEKE, E.O.; OMAFUVBE, B.O. Antibiotic resistance of aerobic mesophilic bacteria isolated from poultry faeces. Research Journal of Microbiology, v.6, n.4, p.356-365, 2011.

BASS, L.; LIEBERT, C.A.; LEE, M.D. et al. Incidence and characterization of integrons, genetic elements mediating multiple-drug resistance, in avian Escherichia coli. Antimicrobial Agents Chemotherapy, v.43, p.2925-2929, 1999.

BARNES, H.J.; VAILLANCOURT, J.P.; GROSS, W.B. Colibacillosis. In: SAIF, Y.M. (Ed.) Diseases of Poultry, 11ed. Ames: lowa State Press, p.631-645, 2003.

BARROS, M.R.; SILVEIRA, W.D.; ARAÚJO, J.M. et al. Resistência antimicrobiana e perfil plasmidial de Escherichia coli isolada de frangos de corte e poedeiras comerciais no Estado de Pernambuco. Pesquisa Veterinária Brasileira, v.32, n.5, 2012.

BLANCO, J.E., BLANCO, M., MORA, A. et al. Prevalence of bacterial resistance to quinolones and other antimicrobials among avian Escherichia coli strains isolated from septicemic and healthy chickens in Spain. Journal of Clinical Microbiology, v.35, n.8, p.2184-2185, 1997.

BRASIL. Portaria $n^{\circ} 193$ de 12 de maio de 1998. Ministério da Agricultura, Pecuária e Abastecimento. Regulamento técnico tara licenciamento e a renovação de licença de antimicrobianos de uso veterinário. Diário Oficial da União 1998, 13 maio.

BRITO, K.C.T.; JAENISCH, F.R.F.; OLIVEIRA, G.A. et al. Resistência antimicrobiana e patogenicidade de amostras de Escherichia coli isoladas de lesões de celulite em frangos. In. XXII Congresso latinoamericano de avicultura, Buenos Aires - Argentina, Congresso... Cepa, 2011.

CARDOSO, A.L.S.P.; KANASHIRO, A.M.I., STOPPA, G.F.Z. et al. Avaliação do perfil de resistência antimicrobiana de Escherichia coli isolada de aves comerciais. Revista Eletrônica Nutritime, artigo 297, v.12, n.1, p.3980-3988, março-abril 2015.

CARDOSO, A.L.S.P.; KANASHIRO, A.M.I., STOPPA, G.F.Z. et al. Resistência antimicrobiana de Escherichia coli isolada de aves comerciais nos Estados de São Paulo e de Goiás, Brasil. Revista Eletrônica Nutritime, artigo 251, v.11, n.3, p.3465-3471, maio-junho 2014.

CLSI. Clinical and Laboratory Standards Institute. Publication M100-S23. Suggested Grouping of US-FDA Approved Antimicrobial Agents That Should Be Considered for Routine Testing and Reporting on Nonfastidious Organisms by Clinical Laboratories, v.33, n.1, 2013.

COHEN, M.L. Changing patterns of infectious diseases. Nature, v.406, p.762-767, 2000.

FERREIRA, A.J.P.; KNÖBL T. Colibacilose Aviária. In: BERCHIERI JÚNIOR, A. \& MACARI, M. Doenças das Aves. Campinas: FACTA, p.197-205, 2000.

GARCIA-MIGURA, L.; HENDRIKSEN, R.S.; FRAILE, L. AND AARESTRUP, F.M. Antimicrobial resistance of zoonotic and commensal bacteria in Europe: The missing link between consumption and resistance in veterinary medicine. Veterinary Microbiology, v.170, p.1-9, 2014.

GIUROV, B.; KORUDZHIISKI, N.; BINEVA, I. Drug resistance of Escherichia coli strains isolated from poultry. Veterinarno-meditsinski nauki, v.18, n.8, p.12-18, 1981.

GOMIS, S.M.; RIDDELL, C.; POTTER, A.A. et al. Phenotypic and genotypic characterization of virulence factors of Escherichia coli isolated from broiler chickens with simultaneous occurrence of cellulitis and other colibacillosis lesions. Canadian Journal Veterinary Research, v.65, p.1-6, 2001.

GONÇALVES, G.A.M.; ANDREATTI FILHO, R.L. Susceptibilidade antimicrobiana de amostras de Escherichia coli isoladas de frango industrial (Gallus Gallus Domesticus Linnaeus, 1758) com colibacilose. Arquivos do Instituto Biológico, São Paulo, v.77, n.4, p.715-718, 2010. 
GONÇALVES, P.M.R.; PEREIRA, V.L.A.; SILVA, R.C.F. et al. Perfil de resistência antimicrobiana de isolados de Escherichia coli positiva para gene iss em frangos de corte na idade de abate. Enciclopédia Biosfera, Centro Científico Conhecer, Goiânia, v.8, n.15, p.1288-1294, 2012.

GRIFFIN, A.M; STUART, C.A. An Ecological Study of the Coliform Bacteria. Journal Bacterioogycal, v.40, n.1, p.83-100, jul. 1940.

ITO, N.M.K.; MIYAJI, C.L.; MIYAJI, S.O. Diagnóstico diferencial das enfermidades bacterianas, fúngicas e parasitárias que acometem os frangos de corte. Cascavel, PR: Coluna do Saber, p.160, 2007.

KIM, T.E.; JEONG, Y.W.; CHO, S.H. et al. Chronological study of antibiotic resistances and their relevant genes in Korean avian pathogenic Escherichia coli isolates. Journal of Clinical Microbiology, v.45, n.10, p.3309-3315, 2007.

KRUMPERMAN, P.H. Multiple antibiotic resistance indexing of Escherichia coli to identify high-risk sources of fecal contamination of foods. Applied and Environmental Microbiology, Washington, v.46, n.1, p.165-170, 1983

McMULLIN, P. Produção avícola após redução do uso de antibióticos. Riscos, potencial de contaminação cruzada e detecção de resíduos. North Yorkshire, U.K., 2004. In: CONFERÊNCIA APINCO, 2., 2004, Campinas SP. Anais... Campinas: FACTA, 2004. v.2, 291p. p.219, 2004.

MOHAMED, M.A.; SHEHATA, M.A.; RAFEEK, E. Virulence genes content and antimicrobial resistance in Escherichia coli from broiler chickens. Veterinary Medicine International, 2014; 2014:195189. doi: 10.1155/2014/195189. Epub 2014 Nov 24.

MOTA, R.A.; DA SILVA, K.P.C.; DE FREITAS, M.F.L. et al. Utilização indiscriminada de antimicrobianos e sua contribuição a multirresitência bacteriana. Brazilian Journal of Veterinary Research and Animal Science, v.42, n.6, p.465-470, 2005.

NAKAZATO,G.; CAMPOS, T.A; STEHLING, E.G. et al. Virulence factors of avian pathogenic Escherichia coli (APEC). Pesquisa Veterinária Brasileira, v.29, p.479-486, 2009.

NEPOMUCENO, L.L.; MACIEL, K.A.; SANTOS, H.D. et al. Susceptibilidade antimicrobiana de cepas de Escherichia coli isoladas de aves condenadas por colibacilose. ISSN 1981-5484, Acta Veterinaria Brasilica, v.10, n.1, p.1-8, 2016.

OBENG, A.S.; RICKARD, H.; NDI, O. et al. Antibiotic resistance, phylogenetic grouping and virulence potential of Escherichia coli isolated from the faeces of intensively farmed and free range poultry. Veterinary Microbiology, v.154, n.3-4, p.305-315, 2012.

SILVA, P.L. Utilização consciente de medicamentos. In: CURSO DE ATUALIZAÇÃO EM AVICULTURA PARA POSTURA COMERCIAL, 5., 2008, Jaboticabal. Anais...Jaboticabal: Funep, p.139-155, 2008.

STELLA, A.E.; De OLIVEIRA, M.C.; FONTANA, V.L.D.S. et al. Padrões da caracterização e resistência a antimicrobianos de Escherichia coli isolada das fezes de frangos de corte saudáveis. Arquivos do Instituto Biológico, v.83, p.1-5, 2016.

VON BAUM, H.; MARRE, R. Antimicrobial resistance of Escherichia coliand therapeutic implications. International Journal of Medical Microbiology, v.295, p.503-511, 2005.

ZANATTA, G.F.; KANASHIRO, A.M.I.; CARDOSO, A.L.S.P. et al. Suscetibilidade de amostras de Escherichia coli de origem aviária a antimicrobianos. Arquivos do Instituto Biológico, v.71, n.3, p.283-286, 2004.

ZHAO, S.; MAURER, J.J.; HUBERT, S. et al. Antimicrobial susceptibility and molecular characterization of avian pathogenic Escherichia coli isolates. Veterinary Microbiology, v.107, p.215$224,2005$.

\section{Recebido em: 16/07/2019 \\ Aprovado em: 24/09/2019}

